\title{
Da palavra ao fio: as tessituras fluidas de Cecilia Vicuña
}

\author{
Márcia Oliveira' ${ }^{1}$ (iD 0000-0002-2995-2158 \\ 'Universidade do Minho, Centro de Estudos Humanísticos, Instituto de Letras e Ciências \\ Humanas, Braga, Minho, Portugal. 4710-057-sec@ilch.uminho.pt
}

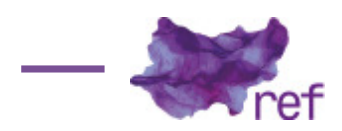

Resumo: No livro La realidade es una línea (1994), Cecilia Vicuña (n. 1947), poeta e artista chilena, sintetiza uma das mais poderosas metáforas que atravessa toda a sua obra visual e poética: a confluência entre fio (objeto) e linha (representação), que urde um tecido complexo feito de experiências e questionamentos que atravessam geografias e géneros artísticos. Se a tecelagem e a sua confluência com a palavra, o som e a imagem, são processo central na obra de Vicuña (real e metafórico), pretendo, neste breve ensaio, explorar a forma como este processo se expande no território do livro, paradoxalmente um lugar de desterritorialização, de fluidez, de construção de um devir - ou de potencialidades - mas também de dissidência.

Palavras-chove: Cecilia Vicuña; palavra; fio; livros de artista

From Word to Thread: Cecilla Vicuña's Fluid Textures

Abstract: In the book La realidade es una línea (1994), Cecilia Vicuña (b. 1947), Chilean poet and artist, synthesizes one of the most powerful metaphors of her visual and poetic work: the confluence between thread (object) and line (representation), which weave a complex fabric made of multiple experiences and questionings that cross geographies and artistic genres. If weaving, and its confluence with word, sound and image, is one of the main processes explored by Vicuña (both in real and metaphorical terms), in this brief article I intend to explore how this process is expanded in the book, here seen as a place of deterritoralization, fluidity, becoming - but also of dissidence.

Keywords: Cecilia Vicuña; word; thread; artists' books

Em La realidade es una línea (VICUÑA, 1994) - A realidade é uma linha - pequeno livro de artista realizado por Cecilia Vicuña em 1994, joga-se com a ideia de que a realidade, assim como a linha, é algo de contínuo e continuamente repetido. Publicado por ocasião da exposição "Hilumbres Allqa/ The Thread Catching Light" na Kanaal Art Foundation (Kortrijk, Bélgica) numa pequena edição de 500 exemplares, o livro constitui-se de uma folha branca dobrada e desdobrável e atada com um fio e na qual surge inscrita a frase homónima do seu título. A frase La realidade es una línea, escrita ao longo da folha branca na horizontal, sem qualquer interrupção, confunde o início e o fim da frase, assim como confunde a linha de tinta que desenha as palavras com o fio feito materialização dessa linha que ata e fecha o corpo do livro. É assim que a obra se presta à ação da leitora que espreita por entre o espaço em branco, aberto, porém fechado na dobragem e na continuidade inesperada que não se lê apenas da esquerda para a direita, mas também da frente para trás, sempre em continuum. Aqui, o fio que envolve o livro em formato desdobrável faz-se linha para desenhar palavra(s), estabelecendo um processo de fluidez entre materialidade e significação, processo central na obra múltipla de Cecilia Vicuña, que diremos tessitura - uma contextura que se desenvolve na linha do desenho, no poema, no fio urdido que se materializa de diferentes formas no espaço, no som, no ritual, elementos que se interligam em 
todas as dimensões da obra desta artista:" "O meu trabalho vagueia pelo que ainda não aconteceu, pelo potencial futuro do que ainda não foi formado, onde som, tecelagem e linguagem interagem para criar novos significados".2

Conhecida pelos seus Precarios, ou Basuritas, pequenas e frágeis assemblagens de fragmentos de materiais pobres, Cecilia Vicuña começou o seu percurso artístico no Chile como pintora, ainda na década de 1960, tendo depois viajado até Londres, onde se encontrava na altura do golpe de Estado em 1973 que determinou também a sua posição de exilada, em Inglaterra e em Nova lorque, EUA. Não só pelo seu percurso, mas também pela relação da sua família que se 'americanizou' por via da atividade artística de várias gerações de mulheres, e pelo contexto político da época, a articulação entre culturas contra a homogeneização cultural sempre foi substrato da sua obra, ${ }^{3}$ articulação essa que encontra uma expressão particularmente fértil na relação entre palavra e fio, numa "prática têxtil-textual que faz referência às histórias silenciadas de mulheres e de indígenas que nunca foram escritas" (LYND, 2005, p. 1590).

Palabra e Hilo (VICUÑA, 1996), publicado em 1996 por ocasião da exposição Precarios, no Royal Botanical Garden de Edimburgo, Escócia, numa edição de 300 exemplares, sintetiza essa ligação mágica entre a palavra e o fio que literalmente atravessa o livro e integra a leitura do poema, atribuindo-lhe dimensões outras que não apenas simbolismo, semântica e significado, numa espécie de mágica que remete para a ideia de complementaridade presente na cultura andina, os seus rituais e processos, que profundamente marcam e determinam o rumo de Vicuña. O fio continua a palavra, atravessa a palavra, torna-se palavra, sendo que a palavra é fio, a palavra interliga e dá continuidade no tempo e no espaço. A palavra atravessa o corpo, e tornase corpo, exatamente como acontece em várias das suas performances, nas quais Vicuña fala e tece em simultâneo. ${ }^{4}$ No livro, o poema, palavra e fio, poeta e tecedeira são indissociáveis; manifestam uma relação íntima, holística, entre estética, espiritualidade e vida: "The thread feels the hand, as the word feels the tongue" / "O fio sente a mão como a palavra sente a língua" (VICUÑA, 1996). Palavra e fio não são só materiais inertes; eles próprios, matéria da arte e da poesia, do olhar e do sentir, são corpo que olha e corpo que sente. Uma relação que se extrai com mais força ainda se tivermos em mente a origem do nome sul-americano Quechua que, como salienta Catherine de ZEGHER (1997a), articula a relação entre texto, têxtil e colaboração. Quechua, diz-nos a curadora, significa o entrelaçamento de dois ou mais fios, mas significa também o entrelaçamento de dois corpos. ${ }^{5}$

Na sua confluência, fio (objeto) e linha (representação, desenho) urdem nestes livros um tecido complexo feito de experiências que atravessam geografias e géneros artísticos. Em La realidade es una línea, o fio que envolve o livro em formato desdobrável faz-se linha para desenhar palavra(s), estabelecendo um processo de fluidez entre materialidade e significação; já Palabra \& Hilo faz os corpos atravessarem-se desse fio: ambos formam "tessituras" que se expandem no território livro,

\footnotetext{
' Ao efetuar um exercício de análise da obra de Gego, em diálogo com o trabalho de Eva Hesse, assim optando por uma metodologia comparativa que pretende ultrapassar limitações culturais e geracionais, Monica AMOR (2008) reflete acerca do carácter indeterminado da linha e do seu papel na obra Reticularéa enquanto elemento central para "explorar o espaço transformado em corpo e vice-versa" ["†o explore space as it becomes form and vice versa"] (p. 84). Amor reconhece a linha como ferramenta primordial que quer Gego, quer Hesse utilizam para "desorganizar os meios convencionais da pintura ["As with Gego, the line [...] seems to have provided Hesse with the perfect tool to disturb the conventional supports of painting and sculpture"] (AMOR, Monica. "On the contingency of modernity and the persistence of canons". In: SMITH, Terry; ENZEWOR, Okwui; CONDEE, Nancy (ed.). Modernity, Postmodernity, Contemporaneity. Durham e Nova lorque: Duke University Press, 2008, p. 85). Este potencial disruptivo e simultaneamente expansivo (em termos espaciais e corporais) da linha está em consonância com o meu argumento em relação ao trabalho de Vicuña e às leituras que esta forma plástica pode convocar enquanto tessitura.

2 "My work dwells in the not yet, the future potential of the unformed, where sound, weaving, and language interact to create new meanings". In: ceciliavicuna.com (todas as traduções do inglês para português são minhas, exceto quando indicada outra autoria).

${ }^{3}$ Janet Lynd explora as relações entre estética e política na obra de Vicuña não só no que diz respeito à sua posição relativamente à ditadura no Chile encabeçada por Augusto Pinochet, mas também, e num sentido mais lato, em termos das hierarquias de poder globais. Como diz a autora, "o trabalho de Vicuña reflete o idealismo da ascensão do socialismo durante os anos Allende, no Chile, a violência do regime militar de Pinochet, a dor do exílio, e a reconceptualização de lutas pela justiça social após o regresso da democracia" ["Vicuña's work reflects the idealism of the rise of socialismo during the Allende years in Chile, the violence of Pinochet's militar regime, the pain of exile, and the reconceptualization of struggles for social justice after the return to democracy"] (LYND, 2005, p. 1590).

${ }^{4}$ Billie Jean ISBELL e Regina HARRISON (1997a) descrevem a performance realizada pela artista em 1994 na Cornell University, EUA, que constituiu uma concretização espacial do seu poema "Antivero". Vicuña movia-se no espaço enquanto desfiava um novelo de fio; num ecrã via-se um rio com vários fios suspensos. Catherine de Zegher salienta as diferentes camadas e interligações convocadas a partir do têxtil (e da tessitura, diríamos), nomeadamente enquanto forma de comunicação, de memória cultural e de significação: "Enquanto forte indicador de padrões culturais - aquilo a que os Maias do México e da Guatemala chamam de costumbre - os têxteis têm o poder de comunicar, mas também um poder poético, económico, ritual e político. Tecer é significar de formas múltiplas" (In ZEGHER, 1997a, p. 26).

5 "Etimologicamente, Quechua significa não só o entrelaçamento de dois (ou mais) fios num cordão, mas também o entrelaçamento de duas pessoas durante a cópula" ["Etymologically Quechua not only means the twine of two (or more) strands twisted together, but also the interlacement of two people copulating"] (ZEGHER, 1997a, p. 19).
} 
arquitetura simultaneamente aberta e fechada, território finito e infinito que permanentemente faze desfaz. Por que falar da obra de Cecilia Vicuña, e dos seus livros em específico, como tessitura? Tessitura, modo como estão interligadas as partes de um todo, organização, contextura é palavra múltipla que se desdobra em sentidos vários na música (significando a disposição das notas para se acomodarem a uma determinada voz ou a um dado instrumento; escala de sons de um instrumento), na palavra (como organização e composição de uma obra literária, narrativa, exposição), na religiosidade (representa também a organização de um discurso religioso). Todas essas dimensões semânticas se encontram interligadas com o ato de tecer, fazer tapeçaria sobre uma tela ou trabalho assim tecido. Como a palavra texto, tessitura encontra raiz no latim "texo, texui, textum, texere, 'tecer, fazer tecido, entrançar, entrelaçar, construir sobrepondo ou entrelaçando'" (Instituto Antônio Houaiss de Lexicografia Portuguesa, 2003, p. 3507): entrelaçar os fios para compor a tapeçaria confunde-se com entrelaçar as palavras - sendo a palavra também o fio do tempo - para compor a história. Todas essas dimensões se materializam na obra de Vicuña, exprimindo-se de forma exemplar nestes livros que apelam aos sentidos mais profundos e subterrâneos da sua cultura andina. Como nota Zegher (1997b), "na língua sagrada Quechua, a palavra para linguagem é 'fio'; a palavra para uma conversação complexa é 'bordado'" (p. 11), , o que contrasta vivamente com a separação ocidental de géneros e práticas artísticas culturais, nas quais o bordado ou a tapeçaria, entre outros, foram sendo reduzidos a práticas artísticas menores, feitas no ambiente doméstico e associadas à esfera do feminino, desprovidas da grandeza das artes ditas maiores, práticas remetidas a uma posição de artesanato (craff), fora da esfera valorativa das chamadas belas-artes (Séverine SOFIO; Perin Emel YAVUZ; Pascale MOLINIER 2007, p. 43). Como nota Whitney CHADWICK (1990), "a ideia de usar tecido como material artístico aglomerou as iconoclastias dos anos de 1970, mas também criou o enquadramento para o desafio feminista à forma como a história da arte reifica certos materiais e processos em detrimento de outros" (p. 363). ${ }^{7}$ A prática da tessitura de Vicuña evoca então não só um modo de expressão feminista, mas também uma prática des-colonial em permanente jogo - o texto, tecido, urdido; o fio que se interconecta com a palavra, com a vida, que não é apenas linha com princípio, meio e fim, incorpora essa originalidade de Vicuña que, segundo Hugo Mendéz-Ramirez,

reside não só na sua bem-sucedida adaptação da poesia oral dos Incas para formas Europeias, e vice-versa, mas também na inclusão da sua experiência pessoal com as mulheres da região dos Andes e no seu conhecimento das diferentes culturas e linguagens andinas. Quechua ou Nahuatl misturam-se com linguagens ocidentais e asiáticas criando uma confusão a partir das suas aparentes diferenças. "Confundir é fundir juntos [(con)fundir], diz Vicuña" (In: ZEGHER 1997b, p. 62). ${ }^{8}$

A partir do exílio, que foi sua condição desde o início da década de 1970, Vicuña magicamente posiciona a sua arte no território da mestiçagem. O seu nome é o mesmo que o do animal sagrado das culturas andinas, a vicunha selvagem, cuja lã era central à economia e à subsistência do povo. Segundo a lenda, as vicunhas nasciam em nascentes de água, e a fibra que se obtinha da sua lã era simbolicamente associada a linhas de cursos de água - fios de água que eram sinónimo do fluxo da vida (Lucy LIPPARD, 1997) e que frequentemente surgem nas suas obras associadas ao fio. Como nota Janet BERLO (1992) no ensaio "Beyond Bricolage: Women and Aesthetic Strategies in Latin American Textiles", os têxteis não só assumem um papel determinante na autorepresentação, veiculando identidades étnicas, religiosas e económicas, mas são também textos históricos, "codificando mudança, apropriação, opressão, resistência, mas também visões estéticas pessoais e culturais" (BERLO, 1992). ${ }^{9}$ Porém, salienta ainda esta autora, "para as latino-americanas indígenas, para as mulheres especificamente, o tecido sempre foi uma forma de discurso alternativo" (lbid.). ${ }^{10} \mathrm{Um}$ discurso alternativo que alimenta e se alimenta dessas relações mágicas entre a palavra e o fio - relações que atravessam o globo e são ao mesmo tempo localizadas e globais -, por exemplo, "em chinês, o caracter king, composto de mi (fio grosso) e de king (curso de água subterrâneo) designa ao mesmo tempo a urdidura dos tecidos e os livros essenciais" (Jean CHEVALIER; Alain GHEERBRANT, 1982, p. 326). No tecido, como no livro, não há estratos, níveis superiores e inferiores; há interconexões, inter-relação, confluência perpétua entre princípio e fim. "Hilo de agua, hilo de vida, hilo de voz", como lemos em quiPOEM (VICUÑA, 1997, q. 124) - o fio atravessando mundos, margens, separações entre terra e água, terra e céu, escuridão e luz. ${ }^{11}$

\footnotetext{
6 "In sacred Quechua, the word for language is 'thread'; the word for complex conversation is 'embroidery'".

7 "The idea of using fabric as an art material both summed up the iconoclasm of the 1970s and established a context within which to mount a feminist challenge to the way art history honored certain materials and certain processes instead of others".

8 "Lies not only in her successful adaptation of the Incas' oral poetry to European forms and vice versa, but also in the inclusion of her own personal experiences with the women of the Andean region and her knowledge of different indigenous cultures and languages. Quechua or Nahuatl intermingle with Asian and Western languages creating a confusion of their apparent differences: "confundir es fundir juntos [(con)fundir], says Vicuña".

9 "Encoding change, appropriation, oppression, endurance as well as personal and cultural aesthetic visions".

10 "For indigenous Latin Americans - especially women, cloth as been an alternative discourse".
} 
O que tece, então, Vicuña nos seus livros: obra visual e poesia? Palabra e hilo, exposição e livro, concretizou-se a propósito da mostra seminal Inside the Visible. An Elliptical Traverse of 20th Century Art (ZEGHER, 1996), com curadoria de Catherine de Zegher, ela própria influenciada pelo processo artístico da artista chilena ("Eu estava a trabalhar com processos abertos", diz Zegher numa entrevista à revista n.paradoxa de Katy DEEPWELL (1996, p. 66)) -, processo aberto, sem fim, ilimitado. Tessitura como narrativa, consciência coletiva e individual, ato político, construção de um quadro cujos fragmentos fazem e desfazem história(s), processualidade em curso, contaminante, contaminada, contaminadora, infinitamente multiplicada... Assim podemos também falar de Saborami, "livro precário e perigoso" como o designa o editor da Beau Geste Press, Filipe Ehrenberg. ${ }^{12}$ Feito em Inglaterra no ano de 1973, Saborami foi concebido como um diário composto por diversos objetos, um por cada dia, cujo objetivo era apoiar o 'processo revolucionário chileno' no âmbito da conspiração política contra o então presidente Salvador Allende. O processo criativo alterou-se com o assassinato de Allende e com o golpe de estado que instituiu o regime militar no Chile. "No início, eu queria prevenir o golpe, mas agora os objetos têm a finalidade de apoiar a luta armada contra o governo reacionário", escreve Vicuña, salientando que tal resistência se faz "política, mágica e esteticamente"13 (VICUÑA, 2011 [1973], p. 12). Documento, diário, livro de poemas, arquivo: Saborami reúne todas essas características apresentando-se como um objeto multidimensional quase inqualificável que põe fragmentos, texto, imagem e objeto a dialogar à luz de um acontecimento histórico mas também para lá desse mesmo acontecimento. Saborami é um livro de memória onde se reúnem poemas, pinturas e outras memórias perante a possibilidade de desaparecem na sequência da censura no Chile que sucedeu ao golpe. Se o livro foi censurado no Chile ainda antes da sua impressão, ${ }^{14}$ esta edição "precária" não deixou de causar indignação também em Londres, onde a artista se encontrava à altura da sua realização e onde apresentou o livro numa exposição no ICA - Institute of Contemporary Arts. Vicuña descreve assim a reação de um professor do Royal College of Art: "Como se atreve a escrever assim? Este livro é um ataque à arte, à poesia e à cultura ocidentais. Você será excluída. Isto é puro lixo" (VICUÑA, 2011 [1973], p. 160). ${ }^{15}$ O trabalho da artista contesta essa colonização intelectual, tornando-se assim frequentemente ininteligível para o público urbano, como nota a própria Vicuña, sendo, no entanto, compreendido por camponeses e pessoas simples. "Há uma lógica oculta que permite que eles compreendam a minha arte. Eles percebem a fertilidade das palavras, a cognição sensual que eu estou a comunicar" (ZEGHER, 1997b, p. 52). ${ }^{16} \mathrm{~A}$ fertilidade das palavras, e essa cognição sensual, nasce em grande medida da origem dessa interligação primitiva entre palavra e fio que entrecruza sensações, corpos, matérias e culturas diversas. No poema Poncho, Vicuña expressa essa "tessitura":

They say wooly anim
Are born high in the
Mountain springs
Water and Fiber
Are one
Wool and cotton
Downy fiber
An open hand
The poncho
Is a book
A woven message
A metaphor

\footnotetext{
"Em 1994, quando da sua participação na exposição Hillumbres Allqa/The Thread Catching Light (Béguinage, Kortrik, Bélgica), Vicuña produziu uma instalação no edifício da comunidade monástica de Béguinage, uma comunidade de mulheres anti-católica fundada na Flandres no século XII e que ainda hoje produz trabalhos em renda. Como descreve a artista, "a minha instalação ocupou três andares do edifício, entretecendo as ruas e jardins envolventes de forma a criar um palimpsesto com a renda Flamenga antiga" (VICUÑA, 1997, q. 138).

${ }^{12}$ Filipe Ehreberg, Some Introductory Notes, In: Vicuña (1973).

13 "In the beginning I wanted to prevent the coup, now the objects intend to support armed struggle against the reactionary government".

${ }^{14} \mathrm{Cf}$. www.ceciliavicuna.com.

15 "How do you dare write like this? This book is an attack on art and poetry and western civilization. You will be erased. This is pure rubbish".

16 "There is a subterranean logic that allows them to understand my art. They understand the fertility of words, the sensual cognition that I am communicating".
} 
Spun. ${ }^{17}$

No livro, o fio enquanto linha, palavra e tempo concretiza todas essas ligações, fazendo com que o objeto livro funcione também como verdadeiro museu portátil, espaço de arquivo, de memória e de evocação, mas também de dissidência (cf. Julia KRISTEVA, 1986). Em Saborami, dentro do livro um outro livro - Cuaderno Café, livro de cartão e veludo feito manualmente entre 1970 e 73 como celebração da revolução chilena e de Salvador Allende. Dentro do livro a pintura, como aquela dedicada à Violeta Parra (camponesa que investigou a tecelagem, a música e a poesia tradicionais chilenas), dentro do livro a poesia, os objetos Precarios, dentro do livro a política, dentro do livro a amizade (uma carta escrita por Francisco Rivera integra o livro original). Dentro do livro também a memória de uma escultura colaborativa, Outono, que resultou da (re)coleção de milhares de folhas de Outono que outrora encheram uma sala do museu de arte de Santiago, no Chile - Saborami completa-se com o diário de conceção e realização dessa peça que nasceu para não ter futuro. O livro é, assim, espaço e tempo na sua relação com o corpo, sendo que, como define Elizabeth GROSZ (1995), "o espaço e o tempo apenas se mantêm imagináveis na medida em que a corporalidade fornece as bases da perceção e da representação que deles mantemos"18 (p. 84). Mas é também um espaço de interrogação privilegiado para perceber as relações entre género e modernidade, na senda do empreendimento de Briony FER (1990) que, no ensaio "What's in a Line", problematiza a possibilidade de falarmos acerca da inscrição de marcas femininas numa obra de arte; como diz a autora, "não defendo que o género seja metafórico; o que digo que é metafórico são as formas que o género pode assumir numa obra de arte". ${ }^{19}$ Não é de somenos importância nesta breve análise o foco no livro de artista enquanto espaço privilegiado para esta reflexão acerca da obra de Vicuña enquanto tessitura - pelas características formais, sentidos metafóricos (poéticos) e materiais (políticos) deste meio artístico específico. Mas, afinal, o que é que existe num livro? Mais do que mera superfície, o livro, ao contrário de outras obras de arte, tem um interior. Por isso, estes objetos constituem obras de arte que não são feitas apenas para serem vistas, ou apreendidas pelo olhar. Eles são obras realizadas para serem efetivamente vividas. Vividas através da leitura, através do toque, do manuseio e das movimentações a que obriga. Por isso, "ver" livros de artista implica também, no fundo, um engajamento, um compromisso com uma série de possíveis interações.

O livro de artista pode ser definido, em primeira instância, como uma "interface dinâmica, um conjunto de códigos estruturados para usar e para aceder à informação e para percorrer a experiência de uma obra" ${ }^{20}$ (Johanna DRUCKER, 1994, p. vii). Uma interface que, em linhas breves, constitui uma síntese entre espaço, tempo e movimento, características que também revestem o livro de artista de uma interessante vocação arqueológica, uma vez que incorpora noções de ritmo, ação e memória que são ativa e construtivamente postas em prática pela leitora em estreita relação com a artista (portanto recetora em relação com produtora).

Diríamos, pois, que o livro de artista integra um potencial expressivo mas também um potencial criativo, o qual reside precisamente nesse seu instinto produtivo, nesse permanente ser outro - radical na sua inacabável criação, bem para lá do momento da concretização da obra pelo artista: política/poiesis. Trata-se, aqui, de dar a ver de forma diferente, uma vez que o livro levanta a importante questão do ato de ver em relação com a arte; a arte do livro não implica apenas ver ou olhar passivamente. Implica, isso sim, um envolvimento de todos os outros sentidos e de diferentes materialidades, pelo muito que exige da sua leitora - espaço, tempo, atenção, dedicação. Ao pôr em evidência os múltiplos caminhos que se colocam à fruição do objeto artístico - uma vez que implica um nível de envolvimento e de intimidade bastante superior ao que sucede com outro tipo de objetos artísticos, o livro de artista coloca-se à artista e à leitora como espaço privilegiado para pôr a dissidência, política e estética, em movimento, em ação, no objeto artístico. Como nota Julia Kristeva (1986) ao defender um novo tipo de intelectualidade que evidencie o potencial de subversão das mulheres, tal subversão existe ao nível de um tipo de discurso extra-verbal (cor, som e gesto surgem aqui como formas de expressão alternativas) e implica um certo grau de marginalidade e de exílio, que pode ocorrer quer física quer intelectualmente. Daí se depreende que o livro de artista, enquanto território de produção artística, mas também enquanto arena de crítica, pode impulsionar a nossa imaginação no sentido de contribuir para esse projeto de escrever sobre as "intervenções feministas na história da arte"

\footnotetext{
17 "Dizem que os animais lanudos/Nascem bem lá no alto/Nas nascentes das montanhas/Água e fibra/São uma/Lã e algodão/Fibra suave/Uma mão aberta/O poncho/É um livro/Uma mensagem tecida/Uma metáfora/fiada" (In: ZEGHER, 1997b, p. 56-57).

18 "Space and time remain conceivable only insofar as corporeality provides the basis for our perception and representation of them".

19 "It is not gender that I am claiming to be metaphorical but the form gender may take in the art work".

20 "The book is a dynamic interface, a structured set of codes for using and accessing information and navigating the experience of a work".
} 
(Griselda POLLOCK, 1999, p. 85), em vez de permanecer eternamente no campo da revisão dessa mesma história enquanto cânone que as mulheres, de uma forma ou de outra, passem a integrar.

Trata-se, no fundo, de olhar a arte partindo da perspetiva que Mieke BAL (2001) reclama para a própria escrita sobre a arte, a qual não pode nunca substituir a arte per se. Ao esboçar qualquer aproximação a uma interpretação ou à produção discursiva do objeto arte, é fulcral perceber o carácter relacional de forma a que o exercício não se torne um vazio e de forma a que todo o seu potencial possa ser descoberto:

Com base na qualidade relacional da obra, trata-se de uma necessidade e de um princípio de abertura em direção aos processos sociais, mas também emocionais, cognitivos e concretos que, à falta de melhor palavra, designamos como estéticos. Mas esta palavra só pode ser usada se for entendida, como sempre deveria ter sido, precisamente nos termos desse processo que envolve corpo e mente, espectadora e obra, numa combinação inextricável ${ }^{21}$ (p. xiv).

E é precisamente esta dinâmica que o livro de artista põe em evidência pelas características amplamente relacionais que definem o seu estatuto, digamos assim, ontológico. Sendo um objeto aparentemente finito, o livro como processo, e não como fim em si mesmo, convoca passado e presente, apresenta-se como infinito pelas possibilidades de des/dobragens e de declinações que permite. No livro, e nos livros de Vicuña comprovadamente, a palavra materializa-se - através do fio, da linha, através da página, mas também através do(s) corpo(s). A palavra torna-se matéria através do real que concretiza o seu potencial criador, (des)dobrando-se infinitamente para dentro e para fora de si num processo interminável e incomensurável: "o livro torna-se carne: incarna o mundo" (Paulo Pires do VALE DO VALE, Gonçalo M. TAVARES; Ana BARATA, 2012, p. 103). O livro tece e é tecido enquanto "sequência de espaço-tempo" (Ulisses CARRIÓN, 1985). Logo, ele próprio é tessitura - conjunto de fragmentos em movimento, objeto fluido, porém uno, indivisível.

\section{Referênclas}

BAL, Mieke. Louise Bourgeois' Spider. The architecture of art-writing. Chicago and London: The University of Chicago Press, 2001.

BERLO, Janet. "Beyond Bricolage. Women and Aesthetics in Latin American Textiles". RES: Anthropology and Aesthetics, n. 22, p. 115-134, 1992.

CARRIÓN, Ulisses. "The New Art of Making Books". In: LYONS, Joan (ed.). Artists' Books: A Critical Anthology and Sourcebook. Nova lorque: Visual Studies Workshop, 1985.

CHADWICK, Whitney. Women, Art, and Society. Londres: Thames \& Hudson, 1990.

CHEVALIER, Jean; GHEERBRANT, Alain. Dicionário de Símbolos. Lisboa: Teorema, 1982.

DEEPWELL, Kathy. "Interview with Catherine de Zegher: Curator of Inside the Visible: An Elliptical Traverse of Twentieth Century Art,in, of, and from the feminine". n.paradoxa. International Feminist Art Journal, n. 1, p. 57-67, 1996.

INSTITUTO ANTÔNIO HOUAISS DE LEXICOGRAFIA PORTUGUESA. Dicionário Houaiss da Língua Portuguesa. Lisboa: Círculo de Leitores, 2003.

DRUCKER, Johanna. The century of artists' books. Nova lorque: Granary Books, 1994.

FER, Briony. "What's in a Line? Gender and Modernity". Oxford Art Journal, v. 13, n. 1, p. 77-88, 1990.

GROSZ, Elizabeth. Space, Time and Perversion. Essays on the Politics of Bodies. Nova lorque e Londres: Routledge, 1995.

ISBELL, Billie Jean; HARRISON, Regina. "Metaphor Spun. A conversation with Cecilia Vicuña". In: ZEGHER, Catherine de (ed.). The Precarios. The Art and Poetry of Cecilia Vicuña. Hanover: University Press of New England, 1997b.

KRISTEVA, Julia. "A New Type of Intellectual: The Dissident”. In: MOI, Toril (ed.). The Kristeva Reader. Oxford: Blackwell Publishers, 1986. p. 292-300.

LIPPARD, Lucy. "Spinning the Common Thread". In: ZEGHER, Catherine. The Precarious. The Art and

\footnotetext{
21 "Based on the relational quality of the work, it is y necessity also a principle of openness toward the social as well as the emotional, cognitive, and effective processes that we call, for lack of a better word, aesthetic. But this word can only be used if it is understood, as it was always meant to be, in terms of precisely that process that involves body and mind, viewer and work, in an inextricable mixture".
} 
Poetry of Cecilia Vicuña. Hanover: University Press of New England, 1997. p. 7-15.

LYND, Janet. "Precarious Resistance: Weaving Opposition in the Poetry of Cecilia Vicuña". PMLA, v. 120, n. 5, p. 1588-1607, 2005.

POLLOCK, Griselda. "Old Bones and Cocktail Dresses: Louise Bourgeois and the Question of Age". Oxford Art Journal, v. 22, n. 2, p. 71-100, 1999.

SOFIO, Séverine; YAVUZ, Perin Emel; MOLINIER, Pascale (ed.). "Genre, Féminisme e valeur de l'art". Cahiers do Genre, Paris, L'Harmattan, v. 23, 2007.

VALE, Paulo Pires do; TAVARES, Gonçalo M.; BARATA, Ana. Tarefas Infinitas: Quando a arte e o livro se ilimitam. Lisboa: Fundação Calouste Gulbenkian, 2012.

VICUÑA, Cecilia. Saborami. Cullompton: Beau Geste Press, 2011 [1973].

VICUÑA, Cecilia. La Realidad es una Linea. Kortrijk: Kanaal Art Foundation, 1994.

VICUÑA, Cecilia. Palabra e Hilo. Translated by Rosa Alcalá. Edinburgh: Morning Star Publications, 1996.

VICUÑA, Cecilia. quiPOEM. Hanover: University Press of New England, 1997.

ZEGHER, Catherine de (ed.). Inside the Visible. An Elliptical Traverse of $20^{\text {th }}$ Century Art. In, of, and from the feminine. Cambridge: MIT Press, 1996.

ZEGHER, Catherine de. "Ouvrage. Knot as Knot, Notes as Knots". In: ZEGHER, Catherine de (ed.). The Precarious. The Art and Poetry of Cecilia Vicuña. Hanover: University Press of New England, 1997a. p. 17-45.

ZEGHER, Catherine de (ed.). The Precarios. The Art and Poetry of Cecilia Vicuña. Hanover: University Press of New England, 1997b.

Márcia Oliveira (marciacoliveira@gmail.com) é doutora em Literatura Comparada e bolseira de pós-doutoramento no Centro de Estudos Humanísticos da Universidade do Minho (bolsa FCT SFRH/BPD/1 10741/2015), onde desenvolve o projeto de investigação intitulado The making of art: tracing feminist processes through $20^{\text {th }}$ Century artists' books. Completou o seu doutoramento em 2013 na Universidade do Minho com tese sobre arte e feminismo em Portugal no período entre 1956 e 1979. As suas publicações mais recentes incluem os artigos "De profundis: a cartography of the face in the work of Paula Rego", no Woman's Art Journal, Rutgers, U.S.A. (no prelo), "Weaving the archive: some notes on Louise Bourgeois' Artists' Books", no JAB - Journal of Artists' Books 42, Fall 2017, Columbia College Chicago Center for Book and Paper Arts, e o livro Arte e Feminismo em Portugal no Contexto Pós-Revolução (Húmus/CEHUM, 2015).

COMO CITAR ESSE ARTIGO DE ACORDO COM AS NORMAS DA REVISTA

OLIVEIRA, Márcia. "Da palavra ao fio: as tessituras fluidas de Cecilia Vicuña". Revista Estudos Feministas, Florianópolis, v. 27, n. 1, e58982, 2019.

CONTRIBUIÇÃO DE AUTORIA

Concepção, elaboração do manuscrito e redação

FINANCIAMENTO

Bolsa de Pós-Doutoramento FCT

CONSENTIMENTO DE USO DE IMAGEM

Não se aplica 
MÁRCIA OLIVEIRA

APROVAÇÃO DE COMITÊ DE ÉTICA EM PESQUISA

Não se aplica

\section{CONFLITO DE INTERESSES}

Não se aplica

\section{LICENÇA DE USO}

Este artigo está licenciado sob a Licença Creative Commons CC-BY. Com essa licença você pode compartilhar, adaptar, criar para qualquer fim, desde que atribua a autoria da obra.

\section{HISTÓRICO}

Recebido em 03/09/2018

Aprovado em 07/09/2018 